\title{
mTOR Pathway and mTOR Inhibitors in Head and Neck Cancer
}

\author{
Wei Gao, John Zeng Hong Li, Jimmy Yu Wai Chan, Wai Kuen Ho, and Thian-Sze Wong
}

Department of Surgery, The University of Hong Kong and Queen Mary Hospital, 102 Pokfulam Road, Hong Kong

Correspondence should be addressed to Thian-Sze Wong, thiansze@graduate.hku.hk

Received 31 July 2012; Accepted 25 September 2012

Academic Editors: J. M. Millan and M. Tahara

Copyright () 2012 Wei Gao et al. This is an open access article distributed under the Creative Commons Attribution License, which permits unrestricted use, distribution, and reproduction in any medium, provided the original work is properly cited.

\begin{abstract}
Head and neck cancer is the sixth most common type of Cancer worldwide. Since conventional treatment regimens are nonselective and are associated with systemic toxicities, intense investigations focus on molecular targeted therapy with high selectivity and low adverse effects. mTOR signaling pathway has been found to be activated in head and neck cancer, making it attractive for targeted therapy. In addition, expression levels of mTOR and downstream targets eIF4E, 4EBP1, S6K1, and S6 are potential diagnostic and prognostic biomarkers for head and neck cancer. mTOR inhibitors, such as rapamycin and its derivatives temsirolimus and everolimus, exhibit inhibitory effects on head and neck cancer in both in vitro cell line model and in vivo xenograft model. A large number of clinical trials have been initiated to evaluate the therapeutic effects of mTOR inhibitors on patients with head and neck cancer. mTOR inhibitor has potential as a single therapeutic agent or in combination with radiation, chemotherapeutic agents, or other targeted therapeutic agents to obtain synergistic repression on head and neck cancer.
\end{abstract}

\section{Introduction}

Head and neck cancer is the sixth most common type of cancer worldwide, with about 650,000 new cases in the world every year [1]. Tobacco and alcohol consumption is a main risk factor for head and neck cancer [1]. In addition, accumulating evidence has shown that human papillomavirus and Epstein-Barr virus are associated with carcinogenesis in oropharyngeal cancers and nasopharyngeal cancers, respectively $[2,3]$. The treatment methods for head and neck cancer include surgery, radiotherapy, and chemotherapy [4]. Patients with early stages of disease are treated by surgery and radiotherapy, while patients with advanced stages of disease are administrated by surgery and chemoradiotherapy [4] Platinum-based agents (cisplatin/carboplatin), taxane agents (docetaxel/paclitaxel), and 5-fluorouracil are the most common chemotherapeutic agents for head and neck cancer [47] (Table 1).

Despite advances in treatment methods for head and neck cancer, the survival rate has not been largely improved [4]. The major reason is that conventional treatment regimens are nonselective and are related with systemic toxicities $[8,9]$. Therefore, intense investigations focus on alternative treatment strategies with less systemic toxicities for head and neck cancer. Since molecular targeted therapy has high selectivity and low adverse effects, it exhibits promise as an alternative treatment strategy for head and neck cancer. Multiple molecular signaling pathways have been found to be dysregulated in head and neck cancer, making it attractive for targeted therapy.

Targeted therapy focuses on oncogenic signaling pathways involved in carcinogenesis of head and neck cancer, such as epidermal growth factor receptor (EGFR), human epidermal growth factor receptor 2 (HER-2), vascular endothelial growth factor receptor (VEGFR), insulin growth factor-1 receptor (IGF-1R), MET receptor, transcriptional factor nuclear factor-kappa B (NF- $\kappa$ B), and phosphatidylinositol-3-kinase (PI3K)/AKT/mammalian target of rapamycin (mTOR) pathway $[10,11]$. Clinical and preclinical investigations have developed some promising targeted agents for head and neck cancer including EGFR inhibitors (cetuximab, panitumumab, zalutumumab, nimotuzumab), EGFR tyrosine kinase inhibitors (gefitinib, erlotinib), dual EGFR/HER-2 kinase inhibitors (lapatinib, afatinib), VEGFR inhibitor (bevacizumab), VEGFR tyrosine kinase inhibitors (sorafenib and sunitinib), IGF-1R inhibitor (figitumumab), MET tyrosine kinase inhibitors (crizotinib, foretinib), mTOR inhibitors (rapamycin, everolimus, temsirolimus, ridaforolimus, Torin1, PP242, and PP30), and proteasome inhibitor (bortezomib) (Figure 1) $[10,11]$. 
TABLE 1: Chemotherapeutic model for head and neck cancer.

\begin{tabular}{|c|c|c|}
\hline Chemotherapeutic agents & Treatment regimens & References \\
\hline $\begin{array}{l}\text { Platinum-based agents } \\
\text { (cisplatin/carboplatin) }\end{array}$ & $\begin{array}{c}\text { Single agent or in } \\
\text { combination with } \\
\text { 5-fluorouracil or taxane } \\
\text { agents }\end{array}$ & {$[5]$} \\
\hline $\begin{array}{l}\text { Taxane agents } \\
\text { (docetaxel/paclitaxel) }\end{array}$ & $\begin{array}{l}\text { In combination with } \\
\text { cisplatin or } \\
\text { 5-fluorouracil }\end{array}$ & {$[6]$} \\
\hline 5-Fluorouracil & $\begin{array}{l}\text { In combination with } \\
\text { cisplatin or taxane } \\
\text { agents }\end{array}$ & [7] \\
\hline
\end{tabular}

mTOR signaling pathway has been found to be activated and expression levels of mTOR and downstream proteins are potential diagnostic and prognostic biomarkers for head and neck cancer. Furthermore, mTOR inhibitors exhibit inhibitory effects on head and neck cancer. Therefore, this paper emphasizes on dysregulated mTOR signaling pathway and the role of mTOR inhibitors in head and neck cancer.

\section{2. mTOR Signaling Pathway in Head and Neck Cancer}

mTOR is an important downstream signal of PI3K/AKT/ mTOR signaling pathway and it is activated in head and neck cancer [12]. The structure of mTOR contains N-terminal tandem HEAT repeats, FAT domain, FATC domain, FRB domain, and C-terminal kinase domain [12]. There are two distinct mTOR complexes designated as mTOR complex 1 (mTORC1) and mTOR complex 2 (mTORC2) (Figure 2) $[13,14]$. mTORC1 is composed of mTOR, regulatory-associated protein of mTOR (Raptor) and mLST8 [15]. mTORC2 is comprised of mTOR, rapamycin-insensitive companion of mTOR (Rictor), mLST8 and mammalian stress-activated protein kinase interacting protein (mSIN1) [14]. mTORC1 is a nutrition- and rapamycin-sensitive complex, while mTORC2 is insensitive to rapamycin $[16,17]$.

mTORC1 is regulated by multiple signals, such as growth factors, nutrients, energy status, and oxygen and cellular stress $[13,14]$. mTORC1 promotes protein synthesis, proliferation, cell survival, ribosome biogenesis, angiogenesis, migration, invasion, and metastasis by phosphorylation of ribosomal protein S6 kinase 1 (S6K1) and eukaryotic initiation factor $4 \mathrm{E}$ (eIF4E)-binding protein 1 (4EBP1) (Figure 2) $[16,18-20]$. The phosphorylation of $4 \mathrm{EBP} 1$ results in the release of eIF4E. Subsequently, the free eIF4E enhances the translation of c-myc, cyclin D1, VEGF, and matrix metalloproteinase-9 (MMP-9), thus promoting cell survival, angiogenesis, invasion and metastasis [21-23]. The activation of S6K1 promotes ribosome biogenesis via upregulation of ribosomal protein S6 [24]. mTORC2 functions in actin remodeling, cell-cycle progression, and cell survival through the regulation of protein kinase $\mathrm{C} \alpha(\mathrm{PKC} \alpha)$ and glucocorticoid-induced protein kinase 1 (SGK1) $[17,25]$.

Some studies have demonstrated that expression levels of mTOR and downstream targets eIF4E, 4EBP1, S6K1, and S6 are potential diagnostic and prognostic biomarkers for head and neck cancer. In an experiment to evaluate mTOR protein expression in 25 patients with laryngeal carcinoma treated with postoperative radiotherapy, it was found that high expression of mTOR was a prognostic marker for high risk of recurrence after postoperative radiotherapy [26]. Elevated level of eIF4E in tumor-free surgical margins was correlated with local-regional recurrence in patients with head and neck cancer [27-29]. Increased level of phosphorylated active form of $\mathrm{S} 6$ was observed in cell lines and tumor tissues from patients with head and neck cancer [29-31]. The mRNA level of $4 E B P 1$ was repressed, while the mRNA expression of $S 6 \mathrm{~K} 1$ was enhanced in tumors of patients with oral squamous cell carcinoma [29]. Expressions of phosphorylated S6K1 and phosphorylated 4EBP1 were regulated by LMP1 and were associated with overall survival of patients with nasopharyngeal carcinoma (NPC), indicating that they were potential prognostic biomarkers for NPC patients [32]. Clark et al. carried out an experiment to find the best molecular markers in the mTOR pathway for head and neck cancer [33]. It was found that phosphorylated mTOR exhibited better sensitivity and specificity than phosphorylated 4EBP1 in differentiating tumor from normal mucosa from patients with head and neck cancer [33].

\section{3. mTOR Inhibitors in Head and Neck Cancer}

mTOR signaling pathway was activated in head and neck cancer, making it attractive for targeted therapy. Two types of mTOR inhibitors designated as first-generation and secondgeneration inhibitors have been developed to interrupt mTOR [34]. First-generation mTOR inhibitors refer to rapamycin and its derivatives temsirolimus, everolimus, and ridaforolimus [14]. Second-generation mTOR inhibitors refer to ATP-competitive mTOR inhibitors including Torin1, PP242, and PP30 [34]. Rapamycin represses the kinase activity of mTOR1 by binding to the FKBP12-rapamycin (FRB) domain of mTORC1 [35]. Since rapamycin has poor water solubility, absorption, and low bioavailability [36], its derivatives are developed to improve bioavailability by a chemical modification at C-40-0 of rapamycin [37]. ATPcompetitive mTOR inhibitors suppress the catalytic activities of both mTORC1 and mTORC2 by binding to the kinase domain [34].

3.1. Inhibitory Effects of Rapamycin on Head and Neck Cancer. Some studies have reported the inhibitory effects of rapamycin on head and neck cancer using both in vitro cell line model and in vivo xenograft model. Rapamycin suppressed growth of SCC-15 cells by inhibiting phosphorylation of mTOR in vitro [38]. Rapamycin prevented tumorigenesis of head and neck cancer in a 4-nitroquinoline-1 oxide carcinogenesis mice model and a k-ras and p53 two-hit carcinogenesis mice model $[39,40]$. Amornphimoltham et al. found that rapamycin treatment significantly repressed 

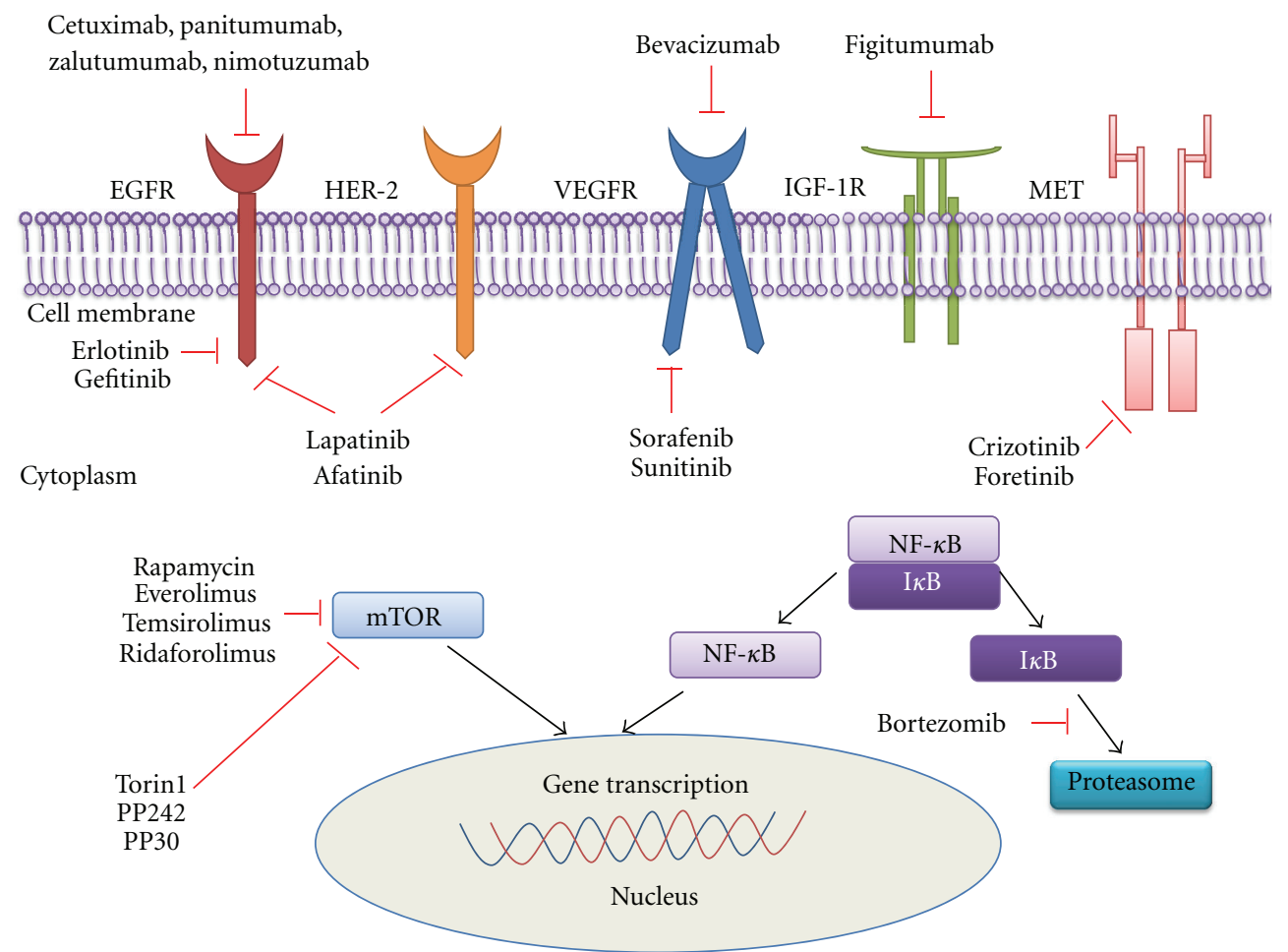

FIGURE 1: Targeted therapies for head and neck cancer. EGFR: epidermal growth factor receptor; HER-2: human epidermal growth factor receptor 2; VEGFR: vascular endothelial growth factor receptor; IGF-1R: insulin growth factor-1 receptor; mTOR: mammalian target of rapamycin; NF- $\kappa$ B: nuclear factor-kappa B.

tumor growth of nude mice bearing xenografts derived from human head and neck cancer cell lines HN21, CAL27, and UMSCC11B [30]. Moreover, it was found that rapamycin inhibited phosphorylation of S6, repressed DNA synthesis, and induced apoptosis in xenograft model [30].

\subsection{Inhibitory Effects of Temsirolimus on Head and Neck} Cancer. The therapeutic effects of temsirolimus on head and neck cancer have also been demonstrated in several studies in both in vitro cell line model and in vivo xenograft model. Temsirolimus treatment inhibited cell proliferation of head and neck cancer cell lines PCI-1 and PCI-13 in vitro [41]. An experiment carried out by Nathan et al. also reported that temsirolimus dose-dependently repressed the proliferation of head and neck cell lines FaDu and FaDu9000 by inhibiting phosphorylation of 4EBP1 in vitro [42]. Furthermore, temsirolimus-treated mice showed reduced tumor size, inhibited phosphorylation of S6, and decreased phosphorylation of 4EBP1 in comparison to control mice in xenograft model [42]. This study has also employed a minimal residual disease (MRD) model to further examine the efficacy of temsirolimus. The MRD model was performed to mimic patients with molecular positive margins. Mice treated by temsirolimus exhibited decreased proportion of mice with tumors, repressed tumor size, and retarded time to develop tumors in comparison with control mice in the MRD model [42]. Finally, it was found that temsirolimus treatment repressed the phosphorylation of $4 \mathrm{EBP} 1$ in peripheral blood mononuclear cells of mice from the MRD model, suggesting that the phosphorylation of 4EBP1 was a promising biomarker to monitor the response of tumors to temsirolimus [42]. Jimeno et al. showed that temsirolimus inhibited the growth of Detroit 562 cells to 13\% in xenograftbearing nude mice. Furthermore, temsirolimus-treated mice displayed a decrease in vessel intratumor growth, while control mice showed widespread vessels in the tumors [43]. These results suggested that temsirolimus inhibited both proliferation and angiogenesis in xenograft model.

3.3. Inhibitory Effects of Everolimus on Head and Neck Cancer. Several studies have also reported the anticancer effects of everolimus on head and neck cancer. Patel et al. found that everolimus and rapamycin inhibited phosphorylated S6 in the primary tumor site and metastatic lymph nodes of mice with UMSCC2-derived xenografts growing in the tongue [44]. In addition, mice treated by everolimus and rapamycin displayed areas of squamous differentiation and fibrosis, while control mice exhibited areas with active cell growth, indicating that everolimus and rapamycin treatment significantly repressed tumor growth [44]. Moreover, everolimusand rapamycin-treated mice showed a reduction in the number of metastatic lymph nodes, resulting in an improvement of the overall survival of mice [44]. Molinolo et al. also reported the inhibitory effects of everolimus and rapamycin on xenografts derived from head and neck cancer cell line UDSCC2 in nude mice [31]. 


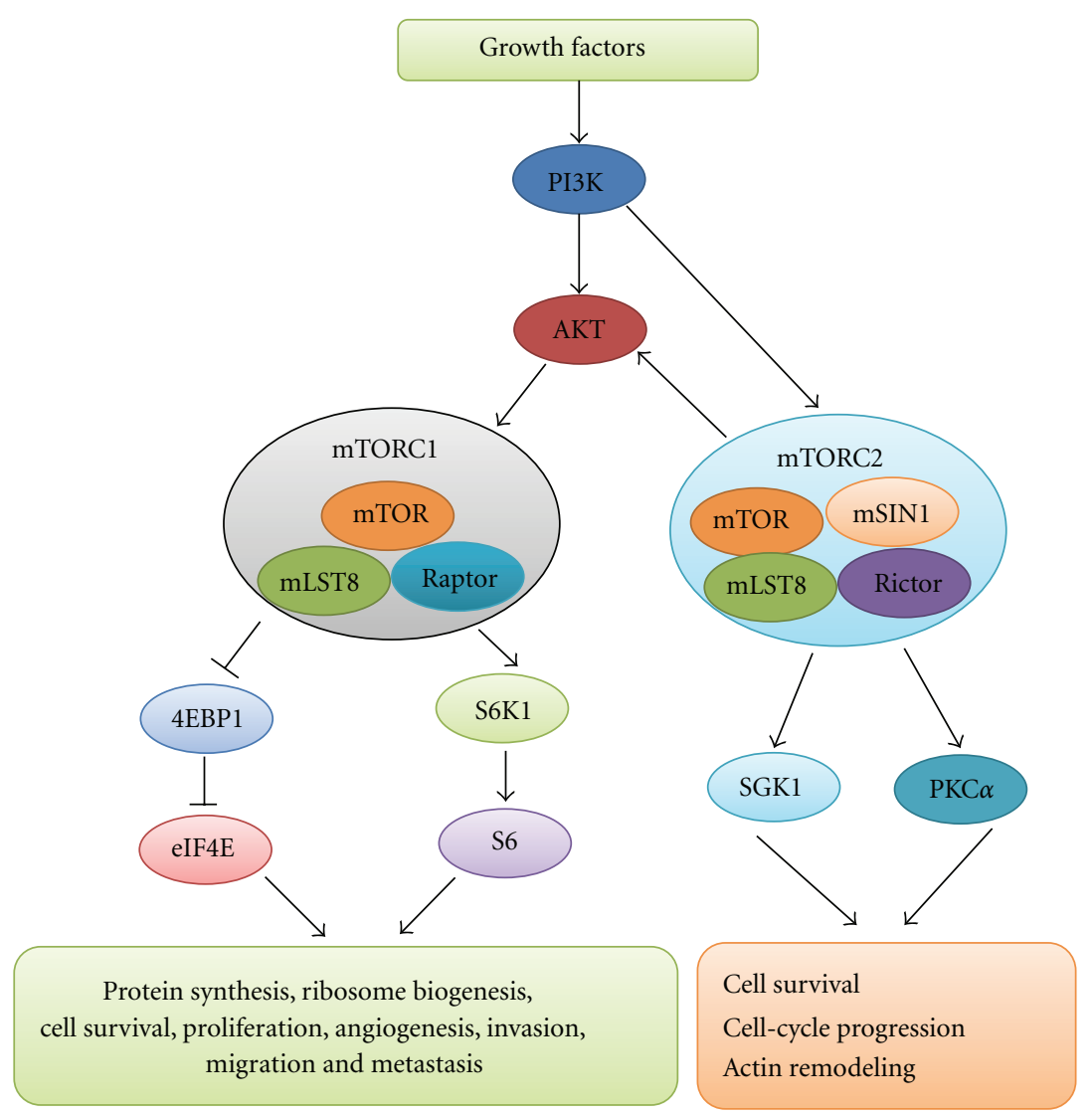

FIGURE 2: mTOR signaling pathway. PI3K: phosphatidylinositol-3-kinase; mTOR: mammalian target of rapamycin; mTORC1: mTOR complex 1; mTORC2: mTOR complex 2; Raptor: regulatory-associated protein of mTOR; Rictor: rapamycin-insensitive companion of mTOR; mSIN1: mammalian stress-activated protein kinase interacting protein; eIF4E: eukaryotic initiation factor 4E; 4EBP1: eIF4E -binding protein 1; S6K1: S6 kinase 1; PKC $\alpha$ : protein kinase C $\alpha$; SGK1: glucocorticoid-induced protein kinase 1.

\section{Clinical Trials on mTOR Inhibitors in Head and Neck Cancer}

Although some studies have demonstrated the inhibitory effects of mTOR inhibitors on head and neck cancer using in vitro cell line model and in vivo xenograft model, little evidence has been obtained from clinical trials. Because most clinical trials were initiated from 2009 to 2011 and are recruiting participants, it is not strange that clinical trials have given little evidence. A phase I clinical trial showed that temsirolimus treatment resulted in partial response in a patient with head and neck cancer at stage T4N3M1 [45]. To evaluate the therapeutic effects of mTOR inhibitors on patients with head and neck cancer, a large number of clinical trials have been initiated (http://www.clinicaltrials.gov/) (Table 2).

\section{Therapeutic Strategies of mTOR Inhibitors in Head and Neck Cancer}

Since mTOR inhibitor alone has displayed inhibitory effects on head and neck cancer, it has potential as a single therapeutic agent. Furthermore, some studies have demonstrated that combined mTOR inhibitors with radiation, chemotherapeutic agents, or other targeted therapeutic agents resulted in synergistic repression on head and neck cancer.

5.1. Evidence on Temsirolimus. Combined temsirolimus with radiotherapy displayed augmented inhibitory effects on tumor growth than radiation alone in mice bearing xenografts derived from head and neck cancer cell lines FaDu and SCC40. Moreover, combined temsirolimus with radiotherapy increased survival of mice with FaDu- and SCC40derived xenografts. These results indicated that temsirolimus could be used in combination with radiotherapy to treat head and neck cancer [46]. Temsirolimus in combination with adriamycin/cisplatin resulted in synergistic suppression of cell proliferation of human head and neck cancer cell line $\mathrm{KB}$ and its multidrug-resistant subclone $\mathrm{KB} / 7 \mathrm{D}$ by inhibiting the phosphorylation of $4 \mathrm{EBP} 1$ and $\mathrm{S} 6 \mathrm{~K} 1$ in vitro [47]. Temsirolimus repressed tumor growth more effectively than erlotinib (an EGFR inhibitor) in nude mice bearing xenografts derived from Detroit 562 cells (intermediate 
TABLE 2: Clinical trials of mTOR inhibitors in head and neck cancer.

\begin{tabular}{|c|c|c|c|}
\hline Drugs & Treatment regimens & Study phase and disease status & Identifier no. \\
\hline Rapamycin & $\begin{array}{l}\text { Rapamycin once daily for } \\
21 \text { days followed by surgery }\end{array}$ & $\begin{array}{l}\text { Phases I/II study in advanced } \\
\text { head and neck cancer }\end{array}$ & NCT01195922 \\
\hline Temsirolimus & $\begin{array}{l}\text { Temsirolimus with or } \\
\text { without cetuximab }\end{array}$ & $\begin{array}{l}\text { Phase II study in recurrent } \\
\text { and/or metastatic head and } \\
\text { neck cancer }\end{array}$ & NCT01256385 \\
\hline Temsirolimus & Temsirolimus & $\begin{array}{l}\text { Phase II study in } \\
\text { relapsed/recurrent } \\
\text { head and neck cancer }\end{array}$ & NCT01172769 \\
\hline Temsirolimus & $\begin{array}{l}\text { Temsirolimus, paclitaxel, } \\
\text { and carboplatin }\end{array}$ & $\begin{array}{l}\text { Phases I/II study in recurrent } \\
\text { or metastatic head and neck } \\
\text { cancer }\end{array}$ & NCT01016769 \\
\hline Temsirolimus & $\begin{array}{l}\text { Temsirolimus, cisplatin, } \\
\text { and cetuximab }\end{array}$ & $\begin{array}{l}\text { Phases I/II study in recurrent } \\
\text { or metastatic head and neck } \\
\text { cancer }\end{array}$ & NCT01015664 \\
\hline Everolimus & $\begin{array}{l}\text { Everolimus, docetaxel, and } \\
\text { cisplatin }\end{array}$ & $\begin{array}{l}\text { Phase I study in local-regional } \\
\text { advanced head and neck } \\
\text { cancer }\end{array}$ & NCT00935961 \\
\hline Everolimus & $\begin{array}{l}\text { Carboplatin, cetuximab, } \\
\text { and everolimus }\end{array}$ & $\begin{array}{l}\text { Phases I/IIB study in recurrent } \\
\text { metastatic head and neck } \\
\text { cancer }\end{array}$ & NCT01283334 \\
\hline Everolimus & $\begin{array}{l}\text { Everolimus, carboplatin, } \\
\text { and paclitaxel }\end{array}$ & $\begin{array}{l}\text { Phases I/II study in locally } \\
\text { advanced head and neck } \\
\text { cancer }\end{array}$ & NCT01333085 \\
\hline Everolimus & Everolimus, cetuximab & $\begin{array}{l}\text { Phase I study in recurrent or } \\
\text { metastatic head and neck } \\
\text { cancer }\end{array}$ & NCT01637194 \\
\hline Everolimus & Everolimus & $\begin{array}{l}\text { Phase II study in refractory, } \\
\text { recurrent, and locally } \\
\text { advanced head and neck } \\
\text { cancer }\end{array}$ & NCT01051791 \\
\hline Everolimus & Everolimus, erlotinib & $\begin{array}{l}\text { Phase II study in recurrent } \\
\text { head and neck cancer }\end{array}$ & NCT00942734 \\
\hline Everolimus & Everolimus, placebo & $\begin{array}{l}\text { Phase II study in locally } \\
\text { advanced head and neck } \\
\text { cancer }\end{array}$ & NCT01133678 \\
\hline
\end{tabular}

susceptibility to erlotinib), indicating that temsirolimus has potential as a therapeutic agent for EGFR-resistant head and neck cancer [43]. Temsirolimus augmented the inhibitory effects of the cetuximab-bevacizumab-irradiation combination in nude mice bearing xenografts derived from head and neck cancer cell line CAL33 [48].

5.2. Evidence on Everolimus. Everolimus displayed inhibitory effects on both cisplatin-resistant and cisplatin-sensitive NPC cell lines in vitro [49]. Combination of everolimus and cisplatin also exhibited synergistic repression on NPC cell lines [49].

\section{Conclusion}

In head and neck cancer, it has been shown that mTOR signaling pathway was activated, making it attractive for targeted therapy. Although some studies have demonstrated the inhibitory effects of mTOR inhibitors on head and neck cancer using in vitro cell line model and in vivo xenograft model, little evidence has been obtained from clinical trials. A large number of clinical trials have been initiated to evaluate the clinical application of mTOR inhibitors in patients with head and neck cancer. Combined mTOR inhibitors with radiation, chemotherapeutic agents, or other targeted therapeutic agents would result in synergistic repression on 
head and neck cancer, thus minimizing their toxicity and overcoming chemoresistant tumors. In addition, mTOR and downstream targets eIF4E, 4EBP1, S6K1, and S6 are potential diagnostic and prognostic biomarkers for head and neck cancer.

\section{References}

[1] D. M. Parkin, F. Bray, J. Ferlay, and P. Pisani, "Global cancer statistics, 2002," Cancer Journal for Clinicians, vol. 55, no. 2, pp. 74-108, 2005.

[2] G. D’Souza, A. R. Kreimer, R. Viscidi et al., "Case-control stud$\mathrm{y}$ of human papillomavirus and oropharyngeal cancer," The New England Journal of Medicine, vol. 356, no. 19, pp. 19441956, 2007.

[3] S. Marur and A. A. Forastiere, "Head and neck cancer: changing epidemiology, diagnosis, and treatment," Mayo Clinic Proceedings, vol. 83, no. 4, pp. 489-501, 2008.

[4] A. Argiris, M. V. Karamouzis, D. Raben, and R. L. Ferris, "Head and neck cancer," The Lancet, vol. 371, no. 9625, pp. 1695-1709, 2008.

[5] S. J. Wong, P. M. Harari, A. S. Garden et al., "Longitudinal oncology registry of head and neck carcinoma (LORHAN)," Cancer, vol. 117, no. 8, pp. 1679-1686, 2011.

[6] M. L. Miller and I. Ojima, "Chemistry and chemical biology of taxane anticancer agents," Chemical Records, vol. 1, no. 3, pp. 195-211, 2001.

[7] D. B. Longley, D. P. Harkin, and P. G. Johnston, "5-Fluorouracil: mechanisms of action and clinical strategies," Nature Reviews Cancer, vol. 3, no. 5, pp. 330-338, 2003.

[8] A. Vissink, J. Jansma, F. K. L. Spijkervet, F. R. Burlage, and R. P. Coppes, "Oral sequelae of head and neck radiotherapy," Critical Reviews in Oral Biology and Medicine, vol. 14, no. 3, pp. 199-212, 2003.

[9] A. Argiris, B. E. Brockstein, D. J. Haraf et al., "Competing causes of death and second primary tumors in patients with locoregionally advanced head and neck cancer treated with chemoradiotherapy," Clinical Cancer Research, vol. 10, no. 6, pp. 1956-1962, 2004.

[10] S. K. Kundu and M. Nestor, "Targeted therapy in head and neck cancer," Tumour Biology, vol. 33, no. 3, pp. 707-721, 2012.

[11] J. P. MacHiels and S. Schmitz, "New advances in targeted therapies for squamous cell carcinoma of the head and neck," AntiCancer Drugs, vol. 22, no. 7, pp. 626-633, 2011.

[12] N. Hay and N. Sonenberg, "Upstream and downstream of mTOR," Genes and Development, vol. 18, no. 16, pp. 19261945, 2004.

[13] Y. M. Liao, C. Kim, and Y. Yen, "Mammalian target of rapamycin and head and neck squamous cell carcinoma," Head and Neck Oncology, vol. 3, no. 1, article 22, 2011.

[14] Y. Y. Zaytseva, J. D. Valentino, P. Gulhati, and B. M. Evers, "mTOR inhibitors in cancer therapy," Cancer Letters, vol. 319, no. 1, pp. 1-7, 2012.

[15] D. H. Kim and D. M. Sabatini, "Raptor and mTOR: subunits of a nutrient-sensitive complex," Current Topics in Microbiology and Immunology, vol. 279, pp. 259-270, 2004.

[16] D. H. Kim, D. D. Sarbassov, S. M. Ali et al., "mTOR interacts with raptor to form a nutrient-sensitive complex that signals to the cell growth machinery," Cell, vol. 110, no. 2, pp. 163$175,2002$.

[17] E. Jacinto, R. Loewith, A. Schmidt et al., "Mammalian TOR complex 2 controls the actin cytoskeleton and is rapamycin insensitive," Nature Cell Biology, vol. 6, no. 11, pp. 1122-1128, 2004.

[18] B. Zhang, H. Cao, and G. N. Rao, "15(S)-hydroxyeicosatetraenoic acid induces angiogenesis via activation of PI3K-AktmTOR-S6K1 signaling," Cancer Research, vol. 65, no. 16, pp. 7283-7291, 2005.

[19] D. D. Sarbassov, S. M. Ali, and D. M. Sabatini, "Growing roles for the mTOR pathway," Current Opinion in Cell Biology, vol. 17, no. 6, pp. 596-603, 2005.

[20] D. C. Fingar, S. Salama, C. Tsou, E. Harlow, and J. Blenis, "Mammalian cell size is controlled by mTOR and its downstream targets S6K1 and 4EBP1/eIF4E," Genes and Development, vol. 16, no. 12, pp. 1472-1487, 2002.

[21] A. De Benedetti and J. R. Graff, "eIF-4E expression and its role in malignancies and metastases," Oncogene, vol. 23, no. 18, pp. 3189-3199, 2004.

[22] I. B. Rosenwald, A. Lazaris-Karatzas, N. Sonenberg, and E. V. Schmidt, "Elevated levels of cyclin D1 protein in response to increased expression of eukaryotic initiation factor 4E," Molecular and Cellular Biology, vol. 13, no. 12, pp. 7358-7363, 1993.

[23] Y. Jiang and R. J. Muschel, "Regulation of matrix metalloproteinase-9 (MMP-9) by translational efficiency in murine prostate carcinoma cells," Cancer Research, vol. 62, no. 6, pp. 1910-1914, 2002.

[24] X. M. Ma and J. Blenis, "Molecular mechanisms of mTORmediated translational control," Nature Reviews Molecular Cell Biology, vol. 10, no. 5, pp. 307-318, 2009.

[25] J. M. García-Martínez and D. R. Alessi, "mTOR complex 2 (mTORC2) controls hydrophobic motif phosphorylation and activation of serum- and glucocorticoid-induced protein kinase 1 (SGK1)," The Biochemical Journal, vol. 416, no. 3, pp. 375-385, 2008.

[26] M. Lionello, S. Blandamura, L. Loreggian et al., "High mTOR expression is associated with a worse oncological outcome in laryngeal carcinoma treated with postoperative radiotherapy: a pilot study," Journal of Oral Pathology \& Medicine, vol. 41, no. 2, pp. 136-140, 2012.

[27] C. A. O. Nathan, S. Franklin, F. W. Abreo, R. Nassar, A. De Benedetti, and J. Glass, "Analysis of surgical margins with the molecular marker eIF4E: a prognostic factor in patients with head and neck cancer," Journal of Clinical Oncology, vol. 17, no. 9, pp. 2909-2914, 1999.

[28] D. L. Sorrells, G. E. Ghali, C. Meschonat et al., "Competitive PCR to detect eIF4E gene amplification in head and neck cancer," Head \& Neck, vol. 21, no. 1, pp. 60-65, 1999.

[29] S. Chakraborty, S. M. A. Azeem, K. S. Gopinath, and A. Kumar, "Involvement of TSC genes and differential expression of other members of the mTOR signaling pathway in oral squamous cell carcinoma," BMC Cancer, vol. 8, article 163, 2008.

[30] P. Amornphimoltham, V. Patel, A. Sodhi et al., "Mammalian target of rapamycin, a molecular target in squamous cell carcinomas of the head and neck," Cancer Research, vol. 65, no. 21, pp. 9953-9961, 2005.

[31] A. A. Molinolo, C. Marsh, M. El Dinali et al., "mTOR as a molecular target in HPV-associated oral and cervical squamous carcinomas," Clinical Cancer Research, vol. 18, no. 9, pp. 2558-2568, 2012.

[32] J. Chen, C. F. Hu, J. H. Hou et al., "Epstein-Barr virus encoded latent membrane protein 1 regulates mTOR signaling pathway genes which predict poor prognosis of nasopharyngeal carcinoma," Journal of Translational Medicine, vol. 8, article 30, 2010.

[33] C. Clark, S. Shah, L. Herman-Ferdinandez et al., "Teasing out the best molecular marker in the AKT/mTOR pathway in head 
and neck squamous cell cancer patients," The Laryngoscope, vol. 120 , no. 6 , pp. 1159-1165, 2010.

[34] D. A. Guertin and D. M. Sabatini, "The pharmacology of mTOR inhibition," Science Signaling, vol. 2, no. 67, p. pe24, 2009.

[35] E. J. Brown, M. W. Albers, T. B. Shin et al., "A mammalian protein targeted by G1-arresting rapamycin-receptor complex," Nature, vol. 369, no. 6483, pp. 756-758, 1994.

[36] A. Crowe, A. Bruelisauer, L. Duerr, P. Guntz, and M. Lemaire, "Absorption and intestinal metabolism of SDZ-RAD and rapamycin in rats," Drug Metabolism and Disposition, vol. 27, no. 5, pp. 627-632, 1999.

[37] Q. Liu, C. Thoreen, J. Wang, D. Sabatini, and N. S. Gray, "MTOR mediated anti-cancer drug discovery," Drug Discovery Today, vol. 6, no. 2, pp. 47-55, 2009.

[38] R. E. Brown, P. L. Zhang, M. Lun et al., "Morphoproteomic and pharmacoproteomic rationale for mTOR effectors as therapeutic targets in head and neck squamous cell carcinoma," Annals of Clinical and Laboratory Science, vol. 36, no. 3, pp. 273-282, 2006.

[39] A. R. Raimondi, A. Molinolo, and J. S. Gutkind, "Rapamycin prevents early onset of tumorigenesis in an oral-specific K-ras and p53 two-hit carcinogenesis model," Cancer Research, vol. 69, no. 10, pp. 4159-4166, 2009.

[40] R. Czerninski, P. Amornphimoltham, V. Patel, A. A. Molinolo, and J. S. Gutkind, "Targeting mammalian target of rapamycin by rapamycin prevents tumor progression in an oral-specific chemical carcinogenesis model," Cancer Prevention Research, vol. 2, no. 1, pp. 27-36, 2009.

[41] F. Schedel, R. Pries, B. Thode et al., "mTOR inhibitors show promising in vitro activity in bladder cancer and head and neck squamous cell carcinoma," Oncology Reports, vol. 25, no. 3, pp. 763-768, 2011.

[42] C. A. O. Nathan, N. Amirghahari, X. Rong et al., "Mammalian target of rapamycin inhibitors as possible adjuvant therapy for microscopic residual disease in head and neck squamous cell cancer," Cancer Research, vol. 67, no. 5, pp. 2160-2168, 2007.

[43] A. Jimeno, P. Kulesza, J. Wheelhouse et al., "Dual EGFR and mTOR targeting in squamous cell carcinoma models, and development of early markers of efficacy," British Journal of Cancer, vol. 96, no. 6, pp. 952-959, 2007.

[44] V. Patel, C. A. Marsh, R. T. Dorsam et al., "Decreased lymphangiogenesis and lymph node metastasis by mTOR inhibition in head and neck cancer," Cancer Research, vol. 71, no. 22, pp. 7103-7112, 2011.

[45] M. J. MacKenzie, S. Ernst, C. Johnson, and E. Winquist, "A phase I study of temsirolimus and metformin in advanced solid tumours," Investigational New Drugs, vol. 30, no. 2, pp. 647-652, 2012.

[46] O. Ekshyyan, Y. Rong, X. Rong et al., "Comparison of radiosensitizing effects of the mammalian target of rapamycin inhibitor CCI-779 to cisplatin in experimental models of head and neck squamous cell carcinoma," Molecular Cancer Therapeutics, vol. 8, no. 8, pp. 2255-2265, 2009.

[47] S. Gaur, L. Chen, L. Yang, X. Wu, F. Un, and Y. Yen, "Inhibitors of mTOR overcome drug resistance from topoisomerase II inhibitors in solid tumors," Cancer Letters, vol. 311, no. 1, pp. 20-28, 2011.

[48] A. Bozec, M. C. Etienne-Grimaldi, J. L. Fischel et al., "The mTOR-targeting drug temsirolimus enhances the growthinhibiting effects of the cetuximab-bevacizumab-irradiation combination on head and neck cancer xenografts," Oral Oncology, vol. 47, no. 5, pp. 340-344, 2011.
[49] B. B. Y. Ma, V. W. Y. Lui, E. P. Hui et al., "The activity of mTOR inhibitor RAD001 (everolimus) in nasopharyngeal carcinoma and cisplatin-resistant cell lines," Investigational New Drugs, vol. 28, no. 4, pp. 413-420, 2010. 


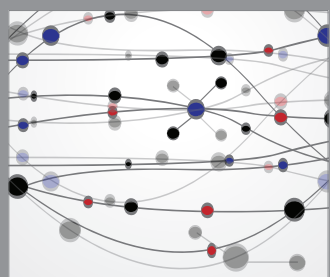

The Scientific World Journal
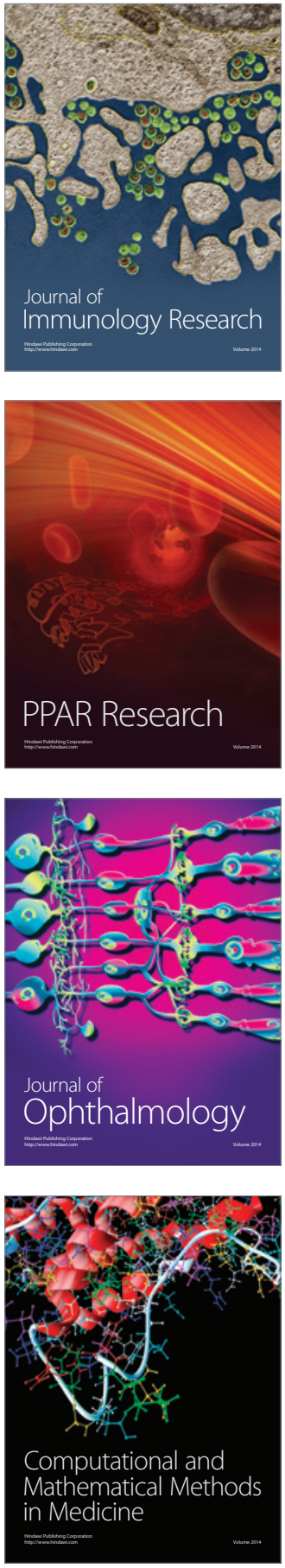

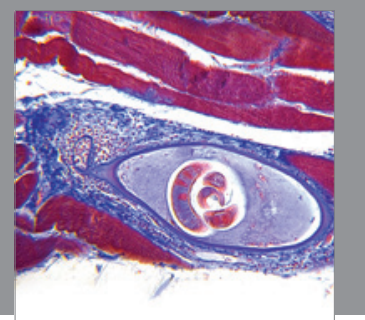

Gastroenterology

Research and Practice
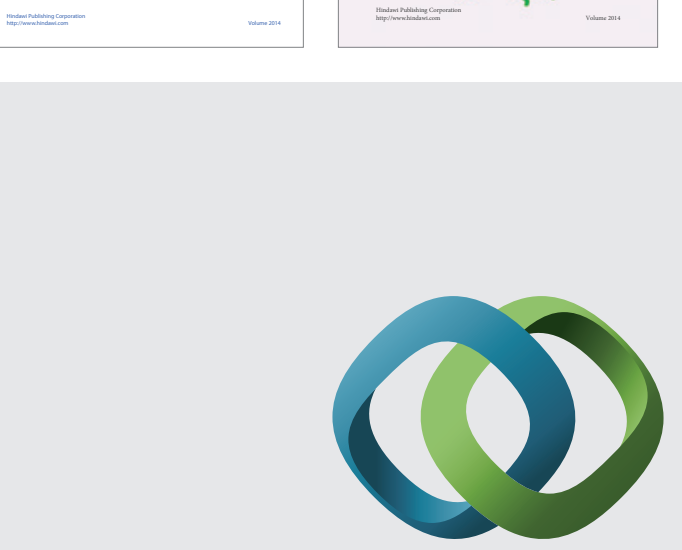

\section{Hindawi}

Submit your manuscripts at

http://www.hindawi.com
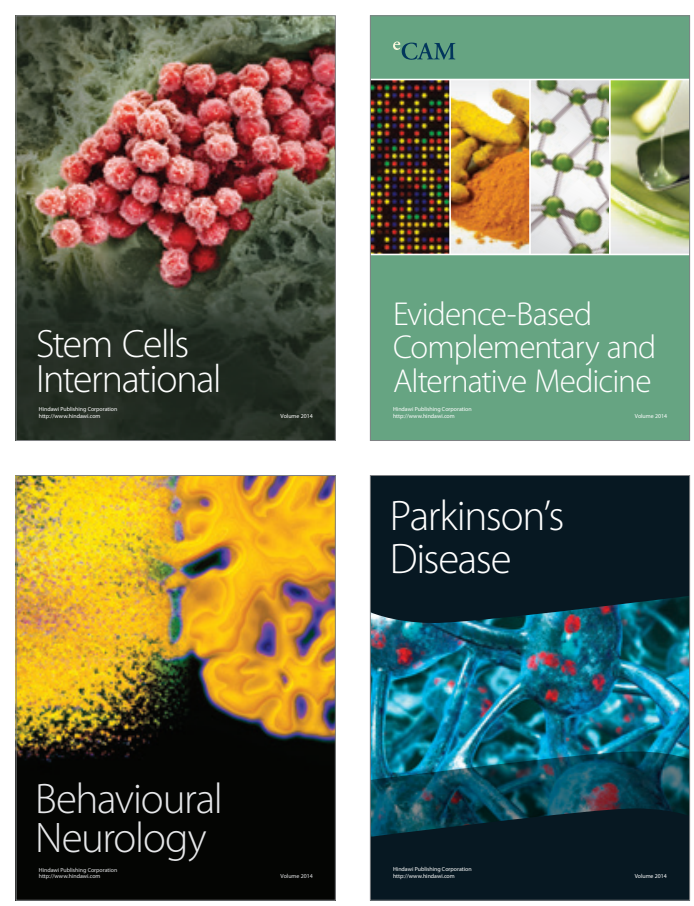

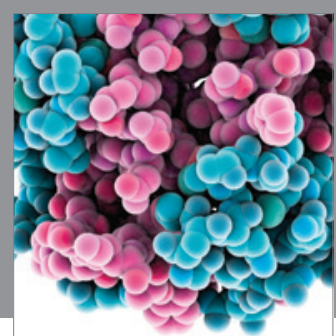

Journal of
Diabetes Research

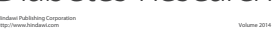

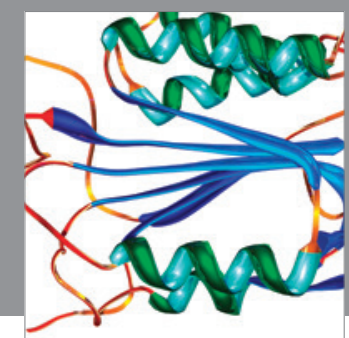

Disease Markers
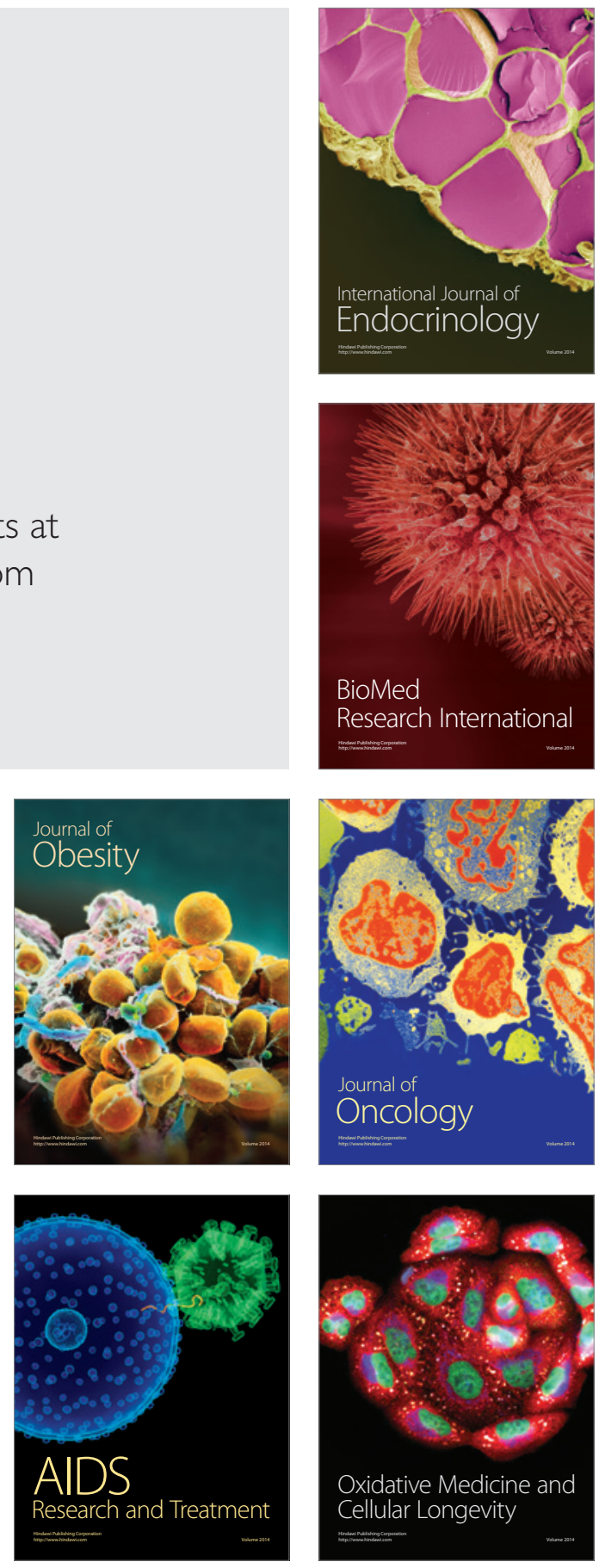